\title{
Characteristic features of winter precipitation and its variability over northwest India
}

\author{
R K YAdAv ${ }^{1, *}$, K Rupa KumaR ${ }^{2}$ and M RAJEevan ${ }^{3}$ \\ ${ }^{1}$ Indian Institute of Tropical Meteorology, Pune, India. \\ ${ }^{2}$ World Meteorological Organization, Geneva, Switzerland. \\ ${ }^{3}$ National Atmospheric Research Laboratory, Tirupati, India. \\ ${ }^{*}$ Corresponding author. e-mail: yadav@tropmet.res.in
}

\begin{abstract}
Northwestern parts of India receive considerable amount of precipitation during the winter months of December-March. Although, it is only about $15 \%$ of the annual precipitation, the precipitation is very important for rabi crops and to maintain the glaciers extend in the Himalaya, which melt and supply water to the rivers during other seasons. The precipitation is mainly associated with the sequence of synoptic systems known as 'western disturbances'. The precipitation has considerable spatial and temporal variability, with maximum precipitation occurring particularly over northern hilly regions, with decreasing influence southwards. The spatially coherent winter precipitation series has been prepared for the largest possible area comprising nine meteorological subdivisions of northwest India, which constitute about $32 \%$ of the total area of the country, having similar precipitation characteristics. The precipitation series has been statistically analysed to understand its characteristics and variability. The seasonal precipitation series is found to be homogeneous, Gaussian (normal) distributed and free from persistence. The precipitation variability has increased during the most recent three decades with more excess and deficient years.
\end{abstract}

\section{Introduction}

The northwestern part of India occupies a vast landmass of about $1,010,654 \mathrm{~km}^{2}$, which roughly lies in the area bounded by $69^{\circ}-85^{\circ} \mathrm{E}$ longitudes and $23^{\circ}-37^{\circ} \mathrm{N}$ latitudes of south Asia (figure 1). It consists of nine meteorological subdivisions of India. This is the main region of food grain production of the country and is famous as 'wheat bowl' of the country. The main precipitation bearing season is during monsoon (June-September), which contributes about $75 \%$ of the annual precipitation. Apart from this, winter season (December-March) contributes only about $15 \%$ of precipitation for the region, but it is very important for rabi crops.
The term rabi means 'spring' in Arabic, when the crop is harvested. Some of the important rabi crops are wheat, barley, peas, gram and mustard. States of north and northeastern part of India such as Punjab, Haryana, Uttar Pradesh and Bihar are important for the production of wheat and other rabi crops. These crops are sown and grown in the winter season, from November to April, and are also known as the 'winter crop'. The winter precipitation is very important for these crops, particularly for wheat, as it supplements the crops with moisture and maintains low temperature by the sweeps of cold and dry air from northern latitudes in the rear of the disturbances, which is very necessary for the development of the crops.

Keywords. Northwest India; winter precipitation; western disturbances; rabi crops; precipitation variability; precipitation epochs. 


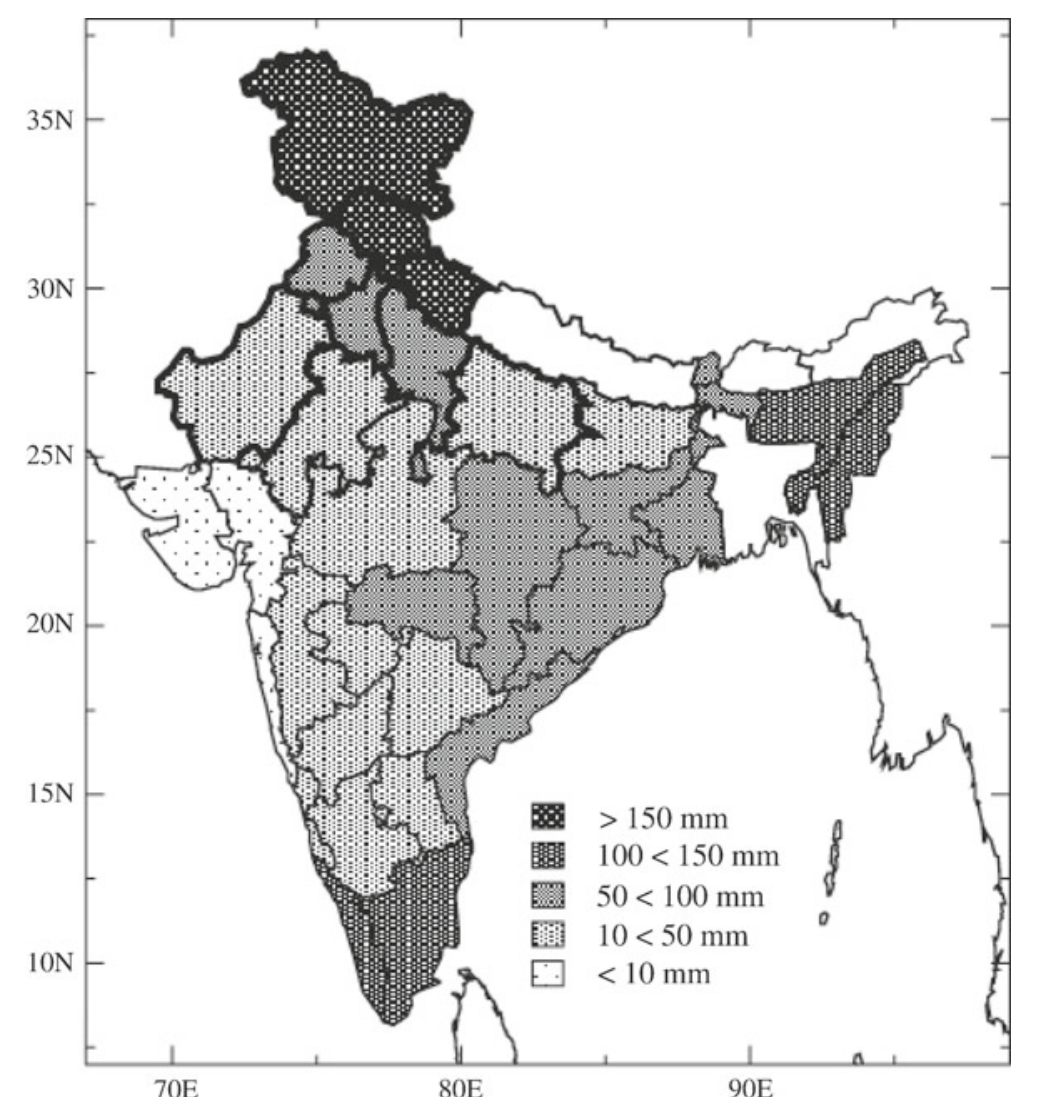

Figure 1. Spatial pattern of seasonal mean climatology of precipitation $(\mathrm{mm})$ for different meteorological subdivisions of India for the season DJFM. The northwest India meteorological subdivisions are shown in thicker lines.

Moreover, the precipitation in the form of snow over the hilly regions of northwest (NW) India helps in maintaining glaciers, which serve as a vast storehouse of water for the great rivers that take their birth in the Himalayas. Water supply to these rivers to dams and canals may suffer deficiency due to drought conditions but will not come to dead stop. The supply of water is used for power generation and irrigation through out the year. Therefore, the season is critically important for the agrarian economy of the country.

The geography of the region plays the leading role in determining the climate. NW India can broadly be divided into three different geographical regions.

- northern mountains including the Himalayas,

- Indo-Gangetic plain and

- Thar desert.

Each region has different geology and fauna-flora. Himalaya, which literally means 'abode of snow', is the highest and one of the youngest mountain ranges on earth. This is a system of huge and lofty mountain ranges bordering the region on the north. It constitutes about $26 \%$ of NW India landmass. The height above which snow cover is perpetual varies from 4500 to $4800 \mathrm{~m}$ on the southern side.
In winter, snowfall takes place at elevations above $1500 \mathrm{~m}$ in the west. The glacier area is about $43,000 \mathrm{~km}^{2}$. The Indo-Gangetic plains form the most important wheat area. The cool winters and the hot summers are very conducive to a good crop of wheat. The plains are often considered India's heartland. In social and economic terms, the IndoGangetic Plain is the most important region of India. It constitutes about $37 \%$ of the landmass of NW India. Topographically the plain is homogeneous and $300 \mathrm{~m}$ above sea level. The Thar desert (also known as The Great Indian Desert), deriving its name from 'thul' denoting the sand ridges of the region, is one of the most inhospitable landscapes on earth. The desert is bordered by the irrigated Indus plains to the west, the Aravalli Range to the southeast and constitutes about $37 \%$ of the area of NW India. The sparsely populated region has a pastoral economy.

During this season (DJFM), with the march of the Sun to southern hemisphere, the whole system of easterly trade and subtropical westerly winds move southwards, and over most of Asia, the winds are westerlies in the middle and upper troposphere. A high-pressure centre of great intensity, called the 'Siberian anticyclone', forms over the northern parts of Asia between $40^{\circ}$ and $60^{\circ} \mathrm{N}$. The outflow 
of cold continental air from this anticyclone in the Asiatic heartland proceeds towards the south and southeast constituting the winter monsoon. This anticyclone, largely formed by the extensive cooling of the landmass, is shallow and extends only upto a level of $700 \mathrm{hPa}$. The subtropical ridge line at $500 \mathrm{hPa}$ level lies between $10^{\circ}$ and $15^{\circ} \mathrm{N}$ from Ethiopia to Vietnam, sloping southwards with height, so that over a major part of the Indian subcontinent the flow pattern is westerly. The upper westerlies increase with height and in the upper troposphere (near $200 \mathrm{hPa}$ ), the flow concentrates into a core of high speed, known as the 'subtropical jet stream' (STJ). The westerly flow is disturbed by the movement of wave perturbations from west to east and the oscillations of the jet stream.

During this period mid-latitude disturbances occurring over the Mediterranean, and sometimes even west over the north Atlantic, get modified over the Persian Gulf and Caspian Sea, come to the lowest latitudes and travel across the north and central parts of India in a phased manner from west to east, disturbing the normal features of circulation patterns (Bhaskara Rao and Morey 1971; Singh and Kumar 1977). These low-pressure systems (Pisharoty and Desai 1956; Mooley 1957; Agnihotri and Singh 1982) are the main source of winter precipitation over NW India. Such weather systems are known in Indian meteorological language as western disturbances (WDs) and are the major synoptic systems that cause these weather activities during winter.

The WDs that move across India appear to have a life history similar to that of the Bjerknes (extra-tropical) cyclones (Pettersen 1956). They arrive over the Indian longitudes more or less in an occluded stage, and therefore do not generally have well-marked cold or warm fronts either at the surface or at upper levels (Singh 1963, 1979; Dutta and Gupta 1987). The highlands and rugged orography of Iran, Afghanistan and western Pakistan obliterate the frontal structure of WDs. WDs and their induced lows that move across NW India as depressions or shallow depressions cause inflow of moist and warm air from Arabian Sea ahead of the depressions, converge in lower levels and contribute to convection and precipitation. Cold and dry air from northern latitudes sweeps in the rear of the disturbances acts as cold waves affecting NW India north of $20^{\circ} \mathrm{N}$.

Compared to the summer monsoon, very few studies have been attempted to understand the variability of NW India winter precipitation (NWIWP). Some noteworthy studies are those of Mooley (1957), Pisharoty and Desai (1956) and Pant and Rupa Kumar (1997). The present study examines the salient features of the climatology of NWIWP using recent data.

\section{Data}

Monthly area-weighted average precipitation series for nine meteorological subdivisions of NW India have been obtained from the records of India Meteorological Department (IMD), for the period 19012006 (106 years). IMD was established in 1875, and has built a long record of climate data spanning over more than a century. It has 559 surface observatories and 701 hydrometeorological observatories spread all over the country. Precipitation is one of the most important meteorological variables, continuously recorded by the IMD and state government agencies with a dense network of more than 4000 raingauge stations. The rabi crop production data has been obtained from Hydrology Section of IMD Pune.

The monthly precipitation series for each of the meteorological subdivisions has been prepared by area-weighted averages of the constituent station precipitation values, by assigning the representative area of each station as the weight. The precipitation data have undergone the relevant quality control tests to ensure homogeneity, for each raingauge station used in this process.

As our objective is to study the variability of winter precipitation over this region, we have considered precipitation from the previous December to concurrent March only. Using precipitation series of these nine subdivisions, area-weighted precipitation series have been prepared for the months December-March as well as the winter season. The precipitation series have been subjected to tests for homogeneity, trend and randomness.

The length of the data series was limited by the availability of the data. However, considering that the World Meteorological Organization (WMO) has adopted 30 years as the period for climatological normals (WMO 1971), it is felt that 105year period is adequate to filter out climatic transients and broadly capture the essential climatic characteristics of NWIWP.

\section{Variability and characteristic features of NWIWP}

\subsection{Homogeneity of precipitation data}

Before analysing the precipitation data series for NW India, it is very essential to test the homogeneity of winter precipitation over each of the nine subdivisions of NW India.

Homogeneity of the precipitation series is tested in the present study using Swed and Eisenhart's test (WMO 1966) of runs above and below the median. The number of runs above and below the median are computed for all subdivisions for the 
months and season and tabulated in table 1. Number of runs less than 44 suggests a trend, and more than 61 suggests an oscillation significant at the $5 \%$ level. Some of the monthly series shows number of runs just below 44 , close to the $5 \%$ confidence level. For the winter precipitation series of all the subdivisions, runs lie between the critical limits, expect for Jammu and Kashmir and west Rajasthan, which are close to lower critical value (44).

\subsection{Climatology of subdivisional winter precipitation}

Figures 1 and 2 show the normal precipitation pattern and annual percentage precipitation contribution of different meteorological subdivisions of India during the winter (DJFM) season, respectively. The extreme southeast (SE) of the peninsular India, where the northeast monsoon (NEM) continues to give some heavy precipitation, and

Table 1. Number of runs above and below median (Swed and Eisenhart's test) for subdivisional monthly winter precipitation over NW India (1902-2004).

\begin{tabular}{|c|c|c|c|c|c|c|}
\hline Subdivision & Name of subdivision & $\mathrm{DEC}$ & JAN & FEB & MAR & SEA \\
\hline 10 & East Uttar Pradesh & $41^{*}$ & 45 & 48 & 50 & 51 \\
\hline 11 & West Uttar Pradesh & 44 & 55 & 52 & 52 & 58 \\
\hline 12 & Uttarakhand & $42^{*}$ & 46 & 56 & 48 & 60 \\
\hline 13 & Haryana, Chandigarh and Delhi & 44 & 57 & 54 & $42^{*}$ & 54 \\
\hline 14 & Punjab & 49 & 51 & 52 & 46 & 50 \\
\hline 15 & Himachal Pradesh & 50 & 57 & 54 & 48 & 46 \\
\hline 16 & Jammu and Kashmir & 53 & $43^{*}$ & 52 & 48 & $42^{*}$ \\
\hline 17 & West Rajasthan & 51 & 49 & 54 & $42^{*}$ & $42^{*}$ \\
\hline 18 & East Rajasthan & 46 & 51 & 50 & 48 & 46 \\
\hline
\end{tabular}

Note: * represents count less than 0.05 confidence level and ** represents more than 0.95 confidence level.

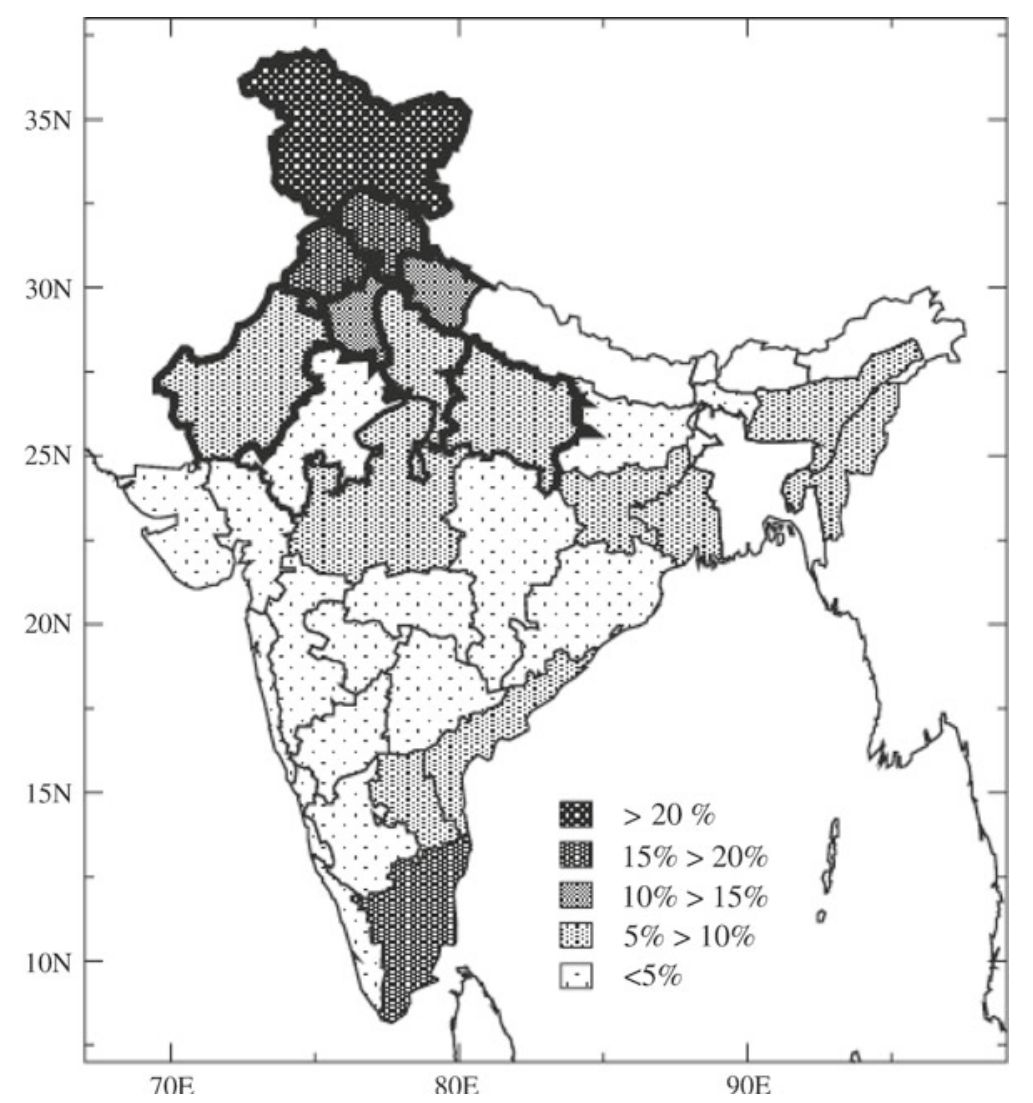

Figure 2. Spatial pattern of percentage of normal annual precipitation contribution for different meteorological subdivisions of India for the season DJFM. The northwest India meteorological subdivisions are shown in thicker lines. 
another area of significant precipitation is NW India, which includes subdivisions like Jammu and Kashmir (J\&K), Himachal Pradesh (HP), Uttarakhand, Punjab and Haryana. Both these regions (SE of peninsular India and NW India), have different precipitation characteristics during this season (DJFM). The precipitation over SE peninsular India has tropical characteristic (convective overturning), while that of NW India has extratropical characteristics. Therefore, NW India region have not been mixed with the SE peninsular India and has been studied separately in this paper. The annual cycle of monthly average and standard deviation of precipitation for each subdivision of NW India are shown in figure 3 . The annual curves show that the precipitation during the winter months for all subdivisions, except Jammu and Kashmir, are much less than during the summer season. The seasonal precipitation, percentage of annual contribution and its variability are presented in table 2 . The regions with higher precipitation show less variability as measured by the coefficient of variation, and vice versa. Heavy precipitation is caused over hilly regions in association with WDs, due to the leading role played by orographic convergence. Over the plain regions, the distribution of precipitation primarily depends on the meteorological conditions. In the mountainous region, the precipitation pattern has larger spatial variability than in the plains. In the plains, the precipitation decreases from west to east as the WDs lose their vigour as they travel eastward. The eastern parts of desert get more precipitation than the western parts due to the presence of the Aravalli Hills. The percentage of annual precipitation is comparable over hilly region where the reach of Indian southwest monsoon is far.

\section{$3.3 N W$ India winter precipitation}

NW India winter precipitation (NWIWP) time series has been prepared as the area-weighted precipitation of nine meteorological subdivisions of NW India. The areas under the different subdivisions are given in table 2 . The total area occupied by NW India is over 1 million $\mathrm{km}^{2}$, which is nearly $32 \%$ of the total area of the country. The

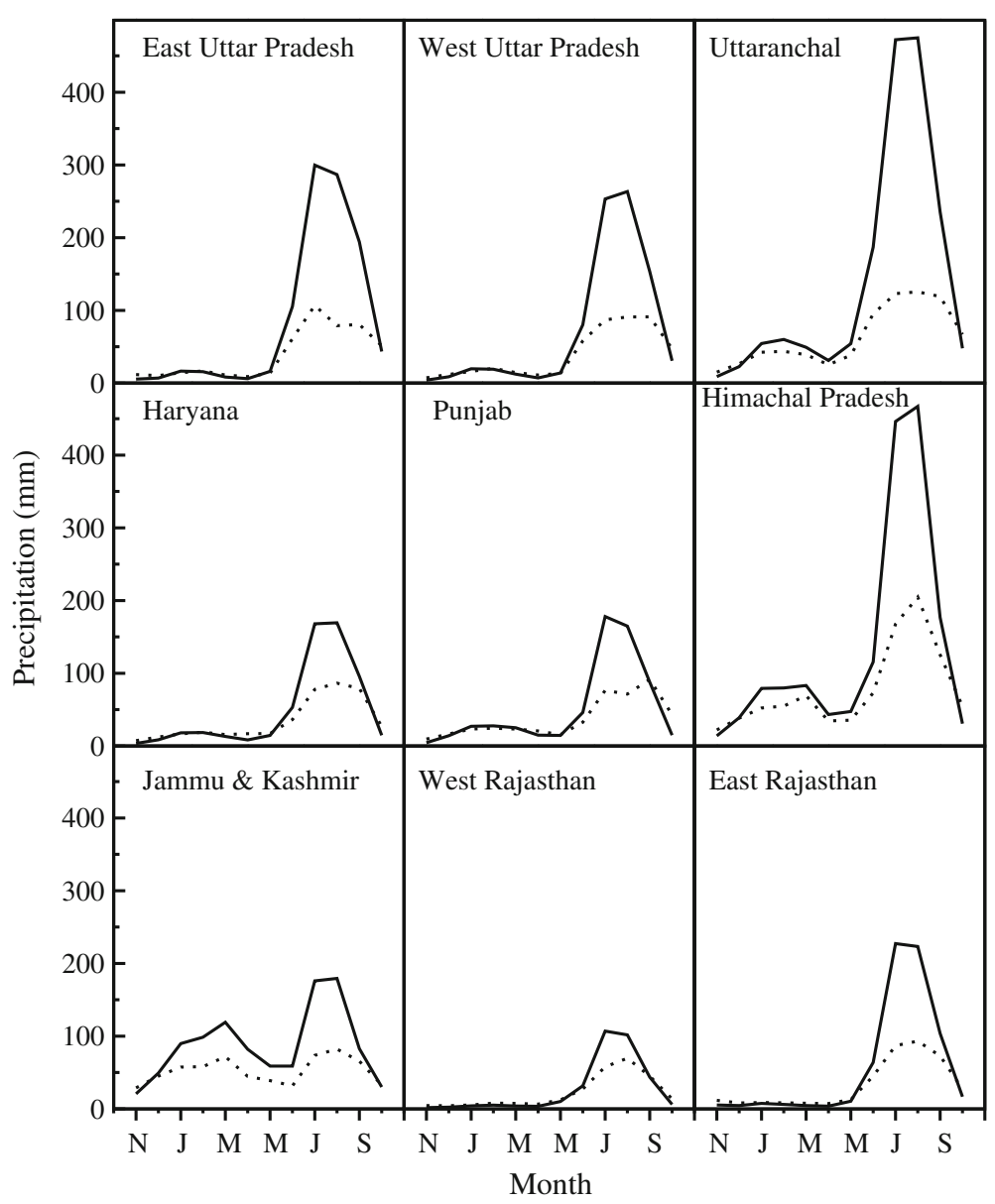

Figure 3. Annual cycle of mean and standard deviation for monthly precipitation of different meteorological subdivisions of NW India for the period 1941-2000. Average (standard deviation) curve is indicated by continuous (dotted) line. 
Table 2. Seasonal (DJFM) mean, \% of annual precipitation (percentage contribution), standard deviation $(S D)$ and coefficient of variation $(C V)$ of precipitation $(\mathrm{mm})$ for each subdivisions of $N W$ India (1902-2004) and its area in square kilometers.

\begin{tabular}{lrcrrr}
\hline Subdivision & $\begin{array}{r}\text { Mean } \\
(\mathrm{mm})\end{array}$ & $\begin{array}{c}\text { \% contribution to } \\
\text { annual precipitation }\end{array}$ & $\begin{array}{c}\text { SD } \\
(\mathrm{mm})\end{array}$ & $\begin{array}{r}\text { CV } \\
(\%)\end{array}$ & $\begin{array}{r}\text { Area } \\
\left(\mathrm{km}^{2}\right)\end{array}$ \\
\hline East Uttar Pradesh & 46.8 & 4.2 & 26 & 55.6 & 146509 \\
West Uttar Pradesh & 59.4 & 5.3 & 31 & 52.1 & 96782 \\
Uttarakhand & 184.9 & 16.6 & 78 & 42.1 & 51122 \\
Haryana & 57.9 & 5.2 & 33 & 56.7 & 45821 \\
Punjab & 93.7 & 8.4 & 44 & 46.6 & 50362 \\
Himachal Pradesh & 278.6 & 25.0 & 119 & 42.7 & 55673 \\
Jammu \& Kashmir & 356.9 & 1.4 & 137 & 38.4 & 222236 \\
West Rajasthan & 15.5 & 2.0 & 12 & 79.6 & 195086 \\
East Rajasthan & 22.5 & & 17 & 74.8 & 147063 \\
\hline
\end{tabular}

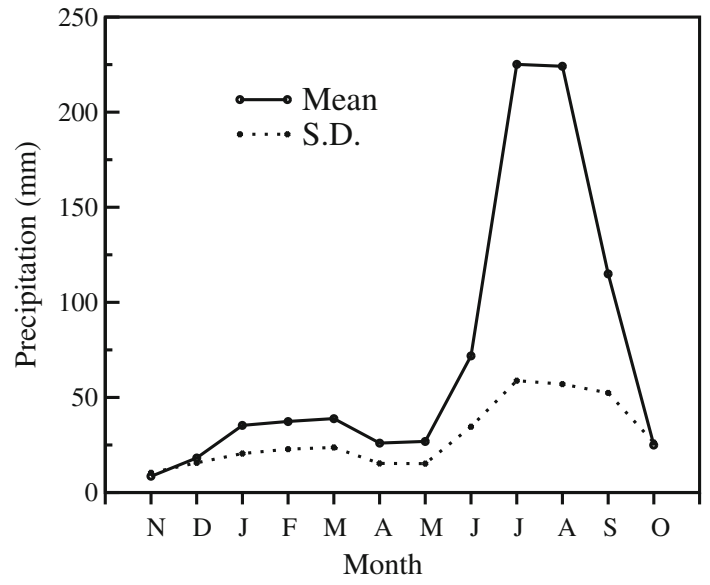

Figure 4. Annual cycle of mean and standard deviation for monthly precipitation of NWIWP for the period 1941-2000.

annual precipitation of NW India as a whole for the period 1901-2004 is $852 \mathrm{~mm}$. The annual cycles of the mean and the standard deviation of NWIWP (figure 4) indicate a secondary maximum of precipitation during the winter months of December through March. The months from DecemberMarch are chosen for NWIWP because it is found that the annual cycle of precipitation reaches a minimum in the month of November and then gradually increases till March. After March there is a second decrease to a minimum in the month of April and then again an increase with the advance of monsoon. More than $50 \%$ of annual precipitation occurs during July and August alone.

Monthly as well as seasonal area-weighted time series have been prepared for NW India as a whole for the period 1902-2004. The statistical parameters, mean, standard deviation (SD), coefficient of variation (CV) and auto correlation coefficients at lag-1 (the lag season is the previous year winter) are computed for each of the winter months
December, January, February and March and for the season as a whole, and are presented in table 3. It can be seen that December contributes the minimum amount of precipitation $(18.2 \mathrm{~mm})$, with maximum CV 85.7\%, whereas March contributes maximum amount of precipitation $38.8 \mathrm{~mm}$ with a CV of $61.8 \%$. The variability is less during January and very high during December. The auto correlations at lag- 1 are too low to suggest any Markovian type of persistence in the precipitation.

The homogeneity of the NWIWP series has been tested by Swed and Eisenhart's test (WMO 1966), and it is found that the runs lie within the critical limits. Therefore, the monthly and seasonal series may be considered to be homogeneous. Further, the linear trends in the monthly and seasonal time series have also been calculated and tested for statistical significance (table 3). None of the series were found to have a trend significant at the $95 \%$ significance level. The NWIWP series has mean $129.5 \mathrm{~mm}$, median $120.7 \mathrm{~mm}$, SD $45.7 \mathrm{~mm}$ and CV $35.3 \%$.

\subsection{Subdivisional inter-correlation of NWIWP}

The winter (DJFM) precipitation series for the NW India as a whole and for each of the nine constituent subdivisions have been analysed to ascertain the degree of inter-correlation. The results are shown in table 4; the numbers 1-9 in the table represent subdivisions East Uttar Pradesh, West Uttar Pradesh, Uttarakhand, Haryana including Delhi and Chandigarh, Punjab, Himachal Pradesh, Jammu \& Kashmir, West Rajasthan and East Rajasthan, in that order. All the nine subdivisions are positively correlated with the NWIWP series, significant at the 99.9\% level. It is also observed that geographically identical subdivisions are very high positively correlated among themselves (e.g., hills, plains and 
Winter precipitation and its variability over $N W$ India

Table 3. Monthly mean precipitation, SD and CV of NWIWP (1902-2004).

\begin{tabular}{lrcccrr}
\hline Month & $\begin{array}{c}\text { Mean } \\
(\mathrm{mm})\end{array}$ & $\begin{array}{c}\text { SD } \\
(\mathrm{mm})\end{array}$ & $\begin{array}{c}\text { CV } \\
(\%)\end{array}$ & $\begin{array}{c}\text { Autocorrelation } \\
(\text { lag 1) }\end{array}$ & Run & Trend \\
\hline December & 18.2 & 15.6 & 85.7 & 0.093 & 49 & 0.0042 \\
January & 35.3 & 20.3 & 57.9 & 0.046 & 47 & -0.0450 \\
February & 37.2 & 22.9 & 61.8 & 0.012 & 52 & 0.0525 \\
March & 38.8 & 23.9 & 61.8 & 0.072 & 44 & 0.0748 \\
Seasonal & 129.5 & 45.7 & 35.3 & 0.114 & 48 & 0.0867 \\
\hline
\end{tabular}

Table 4. Cross-correlations of subdivisional winter season precipitation (1902-2004).

\begin{tabular}{|c|c|c|c|c|c|c|c|c|c|c|}
\hline Subdivision & 1 & 2 & 3 & 4 & 5 & 6 & 7 & 8 & 9 & NWIWP \\
\hline 1 & 1.00 & & & & & & & & & \\
\hline 2 & 0.83 & 1.00 & & & & & & & & \\
\hline 3 & 0.54 & 0.71 & 1.00 & & & & & & & \\
\hline 4 & 0.64 & 0.80 & 0.58 & 1.00 & & & & & & \\
\hline 5 & 0.51 & 0.68 & 0.63 & 0.79 & 1.00 & & & & & \\
\hline 6 & 0.37 & 0.51 & 0.70 & 0.60 & 0.77 & 1.00 & & & & \\
\hline 7 & 0.22 & 0.38 & 0.54 & 0.51 & 0.68 & 0.74 & 1.00 & & & \\
\hline 8 & 0.41 & 0.59 & 0.46 & 0.60 & 0.67 & 0.47 & 0.33 & 1.00 & & \\
\hline 9 & 0.54 & 0.71 & 0.44 & 0.65 & 0.56 & 0.39 & 0.23 & 0.74 & 1.00 & \\
\hline NWIWP & 0.48 & 0.65 & 0.73 & 0.71 & 0.84 & 0.86 & 0.93 & 0.54 & 0.48 & 1.00 \\
\hline
\end{tabular}

deserts). As mentioned in section 1, the geography of the region plays an important role in determining the precipitation characteristic. This clearly indicates that the geographical setting of a region (hilly, plains and desert) plays an important role in modulating the precipitation as well as its variability.

\subsection{Subseasonal inter-correlation of NWIWP}

Information on subseasonal inter-correlations is useful for possible application in long-range forecasts. The inter-correlations among monthly and seasonal winter precipitation (NWIWP) have been computed and presented in table 5 . It can be seen that precipitation in all 4 months is positively correlated with seasonal precipitation and significant at $99 \%$ significant level or above. However, the inter-correlations among the individual months are insignificant. Similar features were also observed in the earlier study for the Indian summer monsoon by Rupa Kumar et al (1992). This suggests that the intra-seasonal oscillations are present within the season and they have significant influence on the inter-annual variability of seasonal NWIWP.

\subsection{Impact of NWIWP on rabi crop production}

To study the impact of NWIWP on rabi crops, which are sown and grown during the same season, we have carried out correlation coefficients (CCs) between detrended rabi crop (wheat, mustard, gram) production and NWIWP. The CCs are -0.43 (February), -0.41 (March), -0.49 (February-March) and -0.41 (DJFM) for the period 1967-2003, which are statistically significant at $95 \%$ level and above. However, the CCs of December and January precipitation with the crop production are not statistically significant. The year-to-year variations of NWIWP during the first and second halves of the season (DJ and FM) and for the whole season (DJFM), and rabi crop production are shown in figure 5(a) and (b), respectively. These results indicate that excessive precipitation during the mature stage of the crops hampers the production. It may be noted that, during the season, the western disturbances are also followed by cold waves and these cold waves are sometimes injurious to these crops, vegetables and fruits.

\subsection{Statistical features of NWIWP}

The frequency distribution of the NWIWP series has been tested for normality by using the chisquare test with 10 equal probability class intervals, as suggested by Cochran (1952). The chisquare value obtained is 16.5 , which is insignificant $(<16.9$ at $5 \%)$ and the series may be considered as Gaussian (normal) distributed. The autocorrelation coefficients at lag-1 is 0.114 , which is too low. 
Table 5. Subseasonal inter-correlations of NWIWP (1902-2004).

\begin{tabular}{lcrccc}
\hline & December & January & February & March & Seasonal \\
\hline December & 1.00 & & & & \\
January & 0.08 & 1.00 & & & \\
February & 0.18 & -0.14 & 1.00 & & \\
March & 0.08 & 0.04 & 0.16 & 1.00 & \\
Seasonal & 0.51 & 0.42 & 0.59 & 0.65 & 1.00 \\
\hline
\end{tabular}
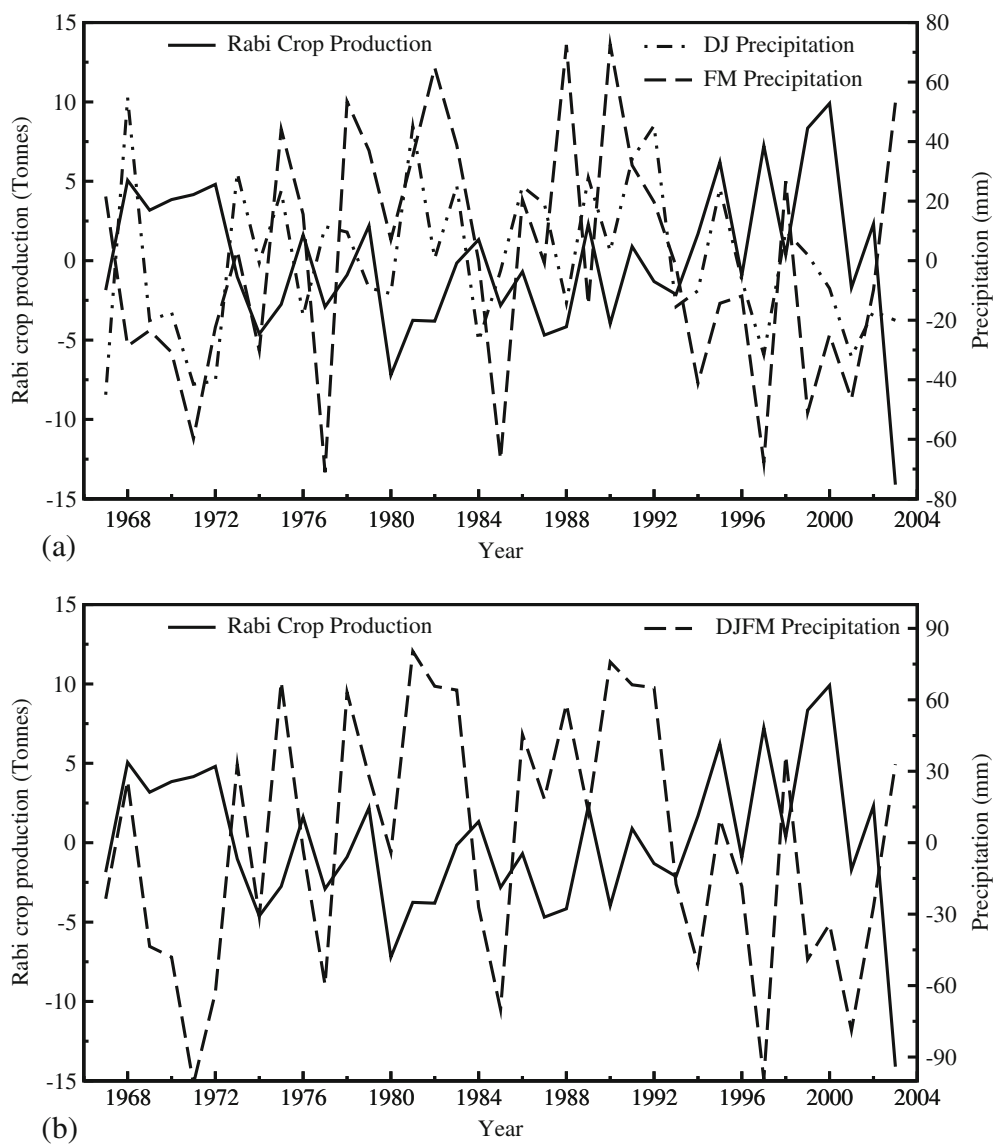

Figure 5. Year-to-year variation of detrend NWIWP and rabi crop production (tonnes) series. Variation of precipitation (a) for the season DJ and FM with rabi crop production and (b) for season DJFM.

This suggests that the series is free from persistence and purely random. The Mann-Kendall rank statistic $(T)_{t}$ for the NWIWP series has been found to be 0.0356 , which is not statistically significant. Therefore, the NWIWP series is considered to be random and free from trend.

\subsection{Excess and deficient years of NWIWP}

The precipitation over NW India exhibits considerable interannual variability. It is very useful to identify the excess and deficient years of NWIWP, to understand their patterns and the associated cyclic behaviour. The NWIWP time series for the period 1902-2005, expressed as the percentage departure from the long period normal, is shown in figure 6 . The excess (deficient) years are defined as those with the precipitation departure greater (smaller) than one coefficient of variation (CV). It is observed that, during the period 1902-2005, there were 19 excess and deficient years. There were three consecutive excess years and two consecutive deficient years (table 6). The highest precipitation recorded is $238.8 \mathrm{~mm}$ (i.e., $183.8 \%$ of the normal) in 1911 and lowest $31.6 \mathrm{~mm}$ (24.3\% of the normal) in 1997. 


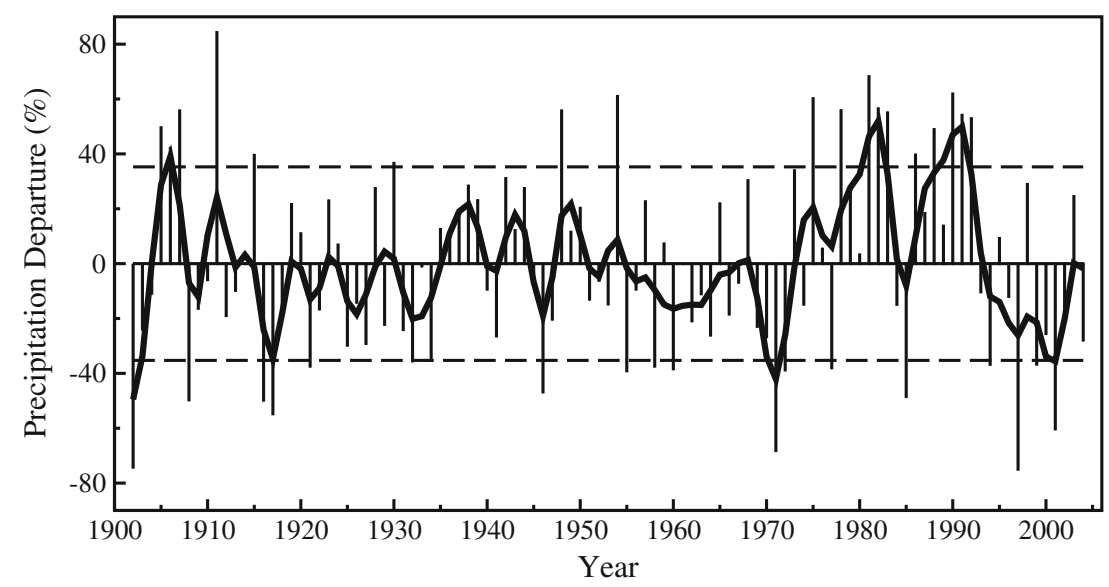

Figure 6. NWIWP time-series for the period 1902-2004 expressed as the percent departure from the long period normal. The horizontal dashed lines refer to $\pm \mathrm{CV}$. The 5-point binomial low-pass filter is shown as continuous line.

Table 6. Excess and deficient precipitation years of NWIWP.

\begin{tabular}{lcccc}
\hline Sl. no. & Excess years & $\begin{array}{c}\text { Precipitation } \\
(\mathrm{mm})\end{array}$ & $\begin{array}{c}\text { Deficient } \\
\text { years }\end{array}$ & $\begin{array}{c}\text { Precipitation } \\
(\mathrm{mm})\end{array}$ \\
\hline 1 & 1905 & 193.9 & 1902 & 32.7 \\
2 & 1906 & 184.2 & 1908 & 64.3 \\
3 & 1907 & 201.8 & 1916 & 64.2 \\
4 & 1911 & 238.8 & 1917 & 57.7 \\
5 & 1915 & 180.9 & 1921 & 80.2 \\
6 & 1930 & 177.1 & 1932 & 82.7 \\
7 & 1948 & 201.8 & 1934 & 83.0 \\
8 & 1954 & 208.7 & 1946 & 68.1 \\
9 & 1975 & 207.7 & 1955 & 78.1 \\
10 & 1978 & 202.0 & 1958 & 80.2 \\
11 & 1981 & 218.0 & 1960 & 79.0 \\
12 & 1982 & 202.9 & 1971 & 40.4 \\
13 & 1983 & 200.9 & 1972 & 78.4 \\
14 & 1986 & 181.0 & 1977 & 79.5 \\
15 & 1988 & 193.0 & 1985 & 65.9 \\
16 & 1990 & 209.8 & 1994 & 81.0 \\
17 & 1991 & 199.8 & 1997 & 31.6 \\
18 & 1992 & 198.2 & 1999 & 81.2 \\
19 & 2005 & 212.4 & 2001 & 50.6 \\
\hline
\end{tabular}

\subsection{Decadal variability of NWIWP}

The low-pass filter curve (WMO 1966) of the precipitation departure series, suppressing the highfrequency oscillations, is also shown in figure 6 . The weights used were the five ordinates of the Gaussian probability curve $(0.06,0.25,0.38,0.25$ and 0.06). The low-pass filter curve is observed to be within the CV limits from 1907 to 1970 (64 years). The curve shows more undulating features from 1902 to 1920 and 1968 to present. During these periods the curve is considerably below normal during 1902-1904 and 1969-1973, showing relatively more frequent deficient years. On the other hand, during 1978-1983 and 1986-1992 there were more excess years. From 1994 to till date, the curve is below normal, depicting a period of below-normal precipitation.

The short-term decadal climate fluctuations have been studied by applying Cramer's test for 11-year running means (WMO 1966). The statistic, which computes 11-year running means of percentage precipitation departure from the overall mean, has been used to isolate periods (if any) of 


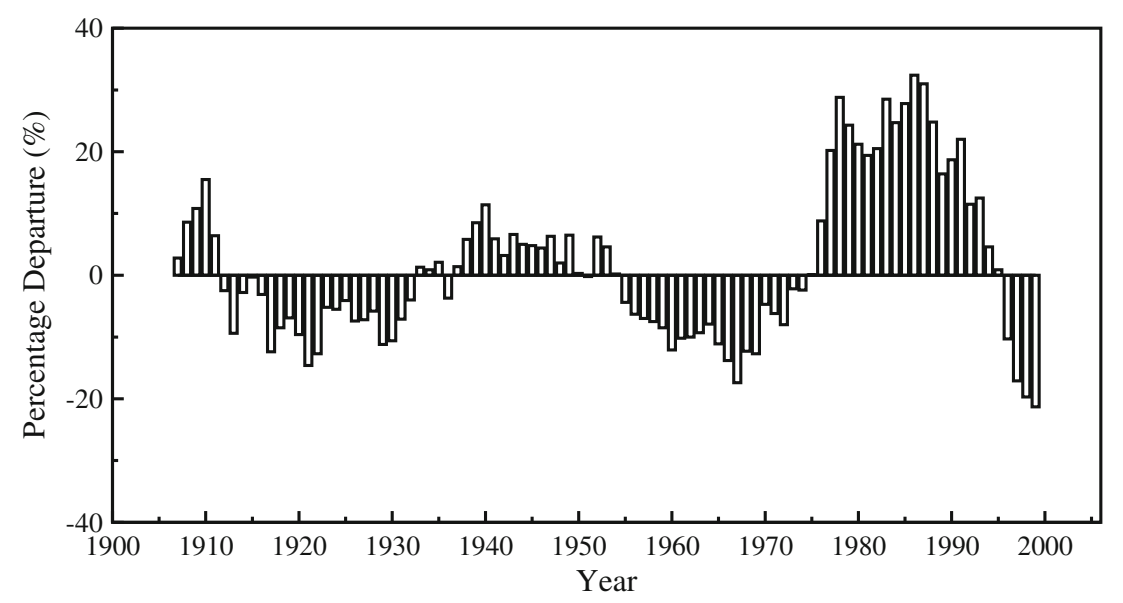

Figure 7. Values of 11-year running mean depicting the short-term decadal climate fluctuations and epoches of above- and below-normal precipitation. Values are plotted at the centre of 11-year period.

above and below average precipitation. The 11-year Cramer's t-statistics are presented in figure 7 . The most striking feature is the epochs of above- and below-normal precipitation. The epochs tend to last for about two decades, which is less than that for the Indian summer monsoon rainfall, for which the epochs tend to last for about three decades (Pant and Rupa Kumar 1997). The variability seems to have increased in amplitude in last three decades.

To examine whether the NWIWP series are free from slippage of mean, 30-year moving $t$ test (Cramer 1946), as suggested by Lawson et al (1981), has been applied. In this test we measure the difference, in terms of a moving $t$-statistic, between the mean for each successive $n$-year period $(n=30)$ and the mean for the entire period. The result for the NWIWP series is shown in the figure 8. It has been found that during the recent period some values of $t$ are greater than the $5 \%$ level of significance. This is due to increased amplitude in the recent period. Otherwise, the series can be considered to be free from slippage of mean.

To study the systematic variations and epochs, the time series has also been subjected to residual mass curve analysis as suggested by Kraus (1956). Here the cumulative percentage departure is plotted against the year (figure 9). Six different climatic periods during the 103-year of NWIWP are clearly seen. These are:

- the gradual increasing tendency during 19021916 (15 years),

- gradual decrease from 1916 up to 1934 (18 years),

- gradual increase from 1934 up to 1954 (20 years),

- gradual decrease from 1954 up to 1972 (18 years),

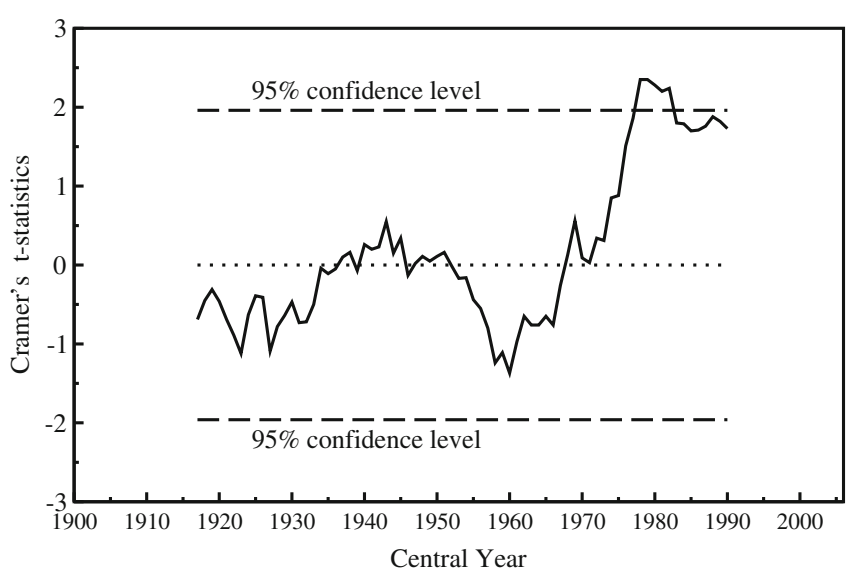

Figure 8. Values of Cramer's $t$-statistics for the 31-year running mean depicting climatological variability and epoches of above- and below-normal precipitation. Values are plotted at the center of 31-year period.

- rather steep increasing tendency from 1972 to 1992 (20 years), and

- steep decreasing tendency from 1992 to 2004 (12 years).

In the earlier studies by Yadav et al (2007, 2009a, 2009b, 2010), it has been shown that the NWIWP is influenced by Indian Ocean sea surface temperatures, North Atlantic Oscillation (NAO) and El Nino Southern Oscillation (ENSO) phenomenons. The NAO influence was maximum between 1940-1980 and decreased in the recent most three decades. Whereas, ENSO influence has strengthened in the recent most three decades. The change of relationship may have changed the variability and epochs of the NWIWP time series. 


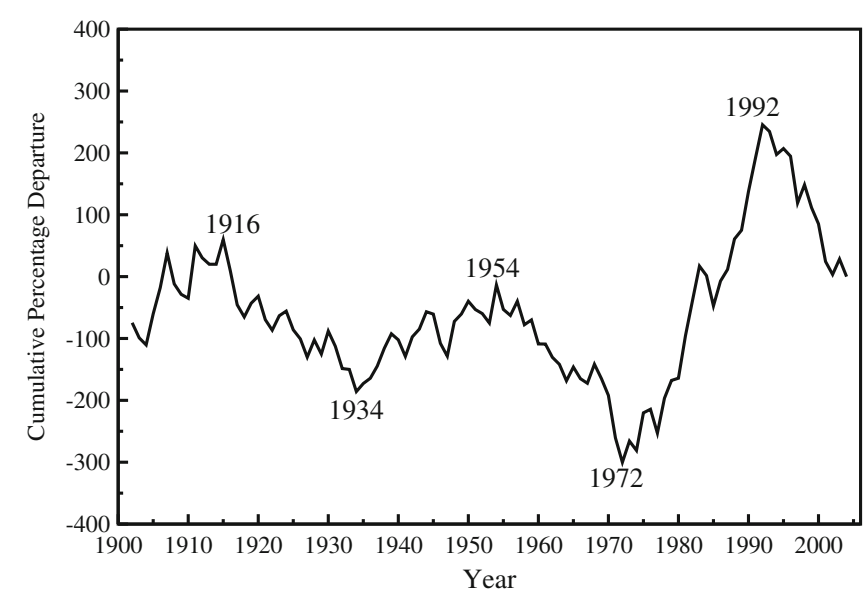

Figure 9. Residual mass curve analysis of NWIWP timeseries for the period 1902-2004 expressed as the cumulative percentage departure from the long period normal.

\subsection{Periodicities in NWIWP}

The NWIWP time series has been subjected to autocorrelation, power spectrum and wavelet analyses to determine if there were any cycles. Autocorrelations are calculated for up to 35 lags. None of the values is statistically significant at $95 \%$ level. Thus, the autocorrelations do not indicate any significant cyclicity in the series. To identify if any cycles are present in the NWIWP, the series are subjected to power spectrum analysis by following the method of Blackman and Tukey (1958) as given in WMO (1966). The power spectrum showing the distribution of spectral estimates up to the maximum lag of 35 is shown in figure 10(a). Here, the $\mathrm{x}$-axis represents the harmonic cycles for 70 years. The dashed lines represent the $99 \%$ and $95 \%$ significant levels. The seasonal precipitation series shows 35-year cycle significant at 95\% significance level. Since there would only be three realizations of that 35 -year period, we only consider periodicities of 10 years or less in the power spectrum. There are no statistically significant peaks of 10 year or less in the spectrum in the NWIWP over the period of study.

Further, we have used continuous wavelet transform analysis (Torrence and Compo 1998) for the NWIWP time series to reveal the non-periodic characteristics of the variability. Wavelet analysis is used to examine non-periodic fluctuations and changing periodicities in a time series. The wavelet power spectrum for the time series shows two bands with 3-7 years and 35-37 years (figure 10b) periodicities. In the case of the wavelets, however, the 35-37 year period is okay to 'let the data reveal itself', since in wavelet analysis the data has not been forced to fit sinusoidal periods, which may or
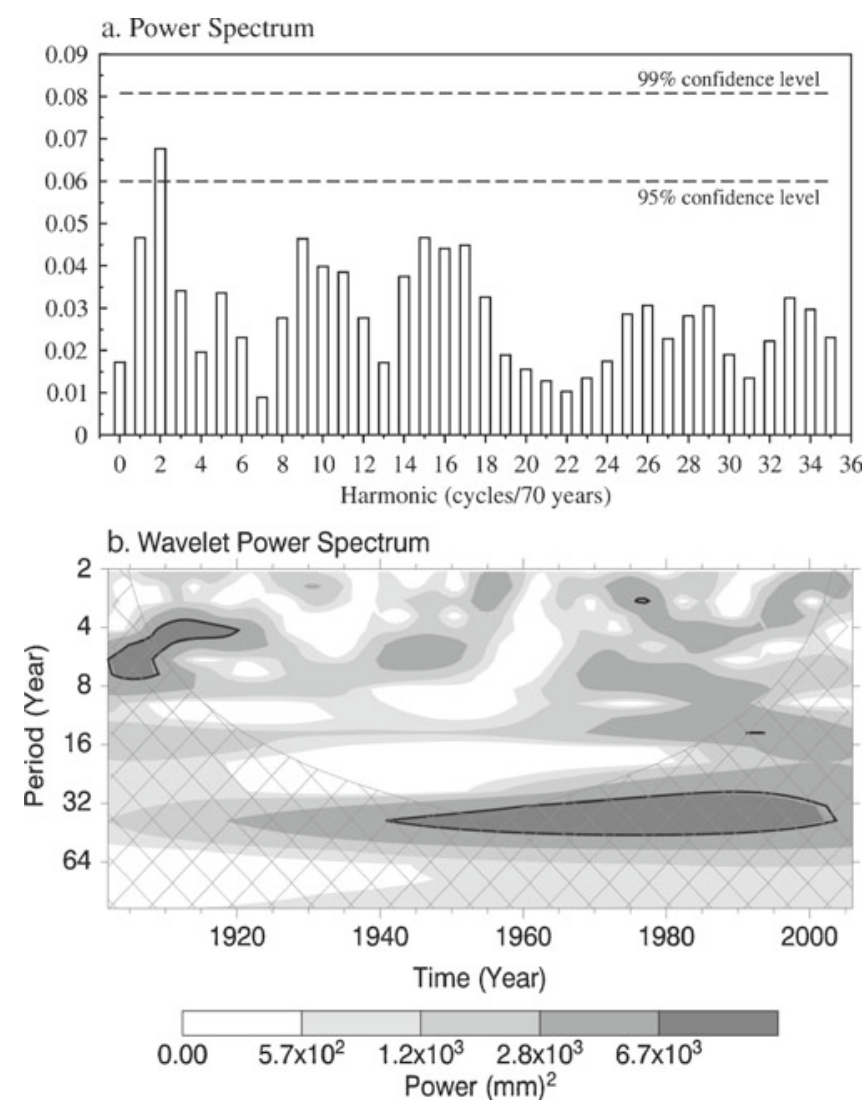

Figure 10. (a) Power spectra of NWIWP. Dashed line shows spectral estimates of confidence levels. (b) The wavelet power spectrum (after Torrence and Campo 1998) for the period (1902-2006). The contour levels are chosen so that $75,50,25$ and $5 \%$ of the wavelet power is above each level, respectively. The cross-hatched region is the cone of influence, where zero padding has reduced the variance. Black contour is the $5 \%$ significance level, using a white-noise background spectrum.

may not exist. The former band shows the precipitation activity was more during 1902-1922, 19431958 and 1973-1998. However, these periodicities are not very strong. The band was strongly significant between 1902 and 1925. The latter band was strongly significant between 1940 and 2004 . It is interesting to note that both the bands, 3-7 years and 35-37 years bands, were active during 1972-1998, which matches with the maximum precipitation variability.

\section{Concluding remarks}

This study examines the characteristic features of winter precipitation and its variability over NW India. During winter season (DJFM), NW India receive considerable amount of precipitation which is mainly associated with the sequence of mid-latitude synoptic systems known as "western disturbances'. Although the winter precipitation 
contribution is only about $15 \%$ of the annual precipitation amount, it is very important for rabi crops sown during the season and to maintain the glaciers extend of the high-altitude regions of the western Himalaya. Since, NW India is divided into three geographical regions: (i) western Himalayas, (ii) Indo-Gangetic plain and (iii) Thar desert, which results in considerable spatial and temporal variability of winter precipitation, with maximum precipitation occurring particularly over northern hilly regions, with decreasing influence southwards. The NW India winter precipitation (NWIWP) time series have been prepared with similar precipitation characteristics and spatially coherent winter precipitation series for the largest possible area comprising nine meteorological subdivisions which constitute about $32 \%$ of the total area of the country. The precipitation series has been statistically analysed to understand its characteristics and variability.

Based on 105 years of precipitation data (from 1902-2006) in the region for the winter months of December-March, the detailed climatology has been studied. The seasonal precipitation series is found to be homogeneous, Gaussian (normal) distributed and free from persistence. Different statistical characteristics of the seasonal and monthly precipitation of the region have been determined. The seasonal precipitation of the region has mean of $130 \mathrm{~mm}$ and SD of $46 \mathrm{~mm}$, with CV of $35.4 \%$. There were 19 deficient and 19 excess years. The inter-annual and intra-seasonal variability analysis shows that the correlation among the precipitation of different months is rather weak, while with season it is very strong. The precipitation variability has increased during the most recent three decades with more excess and deficient years. The precipitation shows clusters of frequent positive and negative departures in the recent three decades.

The 11-year running means suggest the NWIWP variability have increased in amplitude in the recent most three decades. Significant long-term changes (climate shift) in the distribution of tropical Pacific SST and increase in tropical Indian Ocean SST around the mid-1970s have been noted. Therefore, there could be some connection with the recent changes in the ENSO-NWIWP relationships and the mid-1970s climate shift. The increased relationship of NWIWP with Indian Ocean SST and ENSO. The change of relationship may have changed the variability and epochs of the NWIWP time series.

\section{Acknowledgements}

The authors are grateful to the Director, Indian Institute of Tropical Meteorology (IITM), for constant encouragement and providing the necessary facilities to carry out this study. The Indian rainfall data have been provided by the India Meteorological Department (IMD). Computational and graphical analyses required for this study have been done with the free software Red Hat Linux, Intel Fortran and xmGrace.

\section{References}

Agnihotri C L and Singh M S 1982 Satellite study of western disturbances; Mausam 33 249-254.

Bhaskara Rao N S and Morey P E 1971 Cloud systems associated with western disturbances - A preliminary study; IJMG 22(3) 413.

Blackman R B and Tukey J W 1958 The Measurement of Power Spectra (New York, NY: Dover Publication).

Cochran W G 1952 Chi-square test of goodness of fit; Annual Mathematic Statistics 23 315-346.

Cramer H 1946 Mathematical methods in statistics (Princeton, NJ: Princeton Univ. Press), 575p.

Dutta R K and Gupta M G 1987 Synoptic study of the formation and movement of western depression; IJMG $18 \mathrm{E} 45$.

Kraus E B 1956 Graphs of cumulative residuals; Quart. J. Roy. Meteor. Soc. 82 96-97.

Lawson M P, Balling R C J Jr, Peters A J and Rundquist D C 1981 Spatial analysis of secular temperature fluctuations; J. Climatol. 1 325-332.

Mooley D A 1957 The role of western disturbances in the production of weather over India during different seasons; Indian J. Meteor. Geophys. 8 253-260.

Pant G B and Rupa Kumar K 1997 Climate of South Asia; Wiley, New York.

Pettersen S 1956 Weather Analysis and Forecasting; Vol. 2D: McGraw-Hill, 422p.

Pisharoty P R and Desai B N 1956 Western disturbances and Indian weather; Indian J. Meteor. Geophys. $8333-$ 338.

Rupa Kumar K, Pant G B, Parthasarathy B and Sontakke N A 1992 Spatial and subseasonal patterns of the longterm trends of Indian summer monsoon rainfall; Int. J. Clim. 12 257-268.

Singh M S 1963 Upper air circulation associated with a western depression; IJMG 14(3) 156.

Singh M S 1979 Westerly upper air troughs and development of western depression over India; Mausam 30(4) 405414.

Singh M S and Kumar S 1977 Study of western disturbances; Indian J. Met. Hydrol. Geophys. 28(2) 233-242.

Torrence C and Compo G P 1998 A practical guide to wavelet analysis; Bull. Amer. Meteor. Soc. 79 61-78.

WMO (World Meteorological Organizatioin) 1971 A note on climatological normals: WMO Technical Note No. 84, WMO No. 208-TP-108, Geneva.

WMO (World Meteorological Organizatioin) 1966 Climate change, WMO Technical Note No. 79, WMO No. 195-TP100, Geneva.

Yadav R K, Rupa Kumar K and Rajeevan M 2007 Role of Indian Ocean sea surface temperatures in modulating northwest Indian winter precipitation variability; Theor. Appl. Climatol. 87 73-83, doi: 10.1007/s00704-0050221-5.

Yadav R K, Rupa Kumar K and Rajeevan M 2009a Out-of-phase relationships between convection over north-west India and warm-pool region during winter 
season; Int. J. Climatol. 29 1330-1338, doi: 10.1002/ joc. 1783 .

Yadav R K, Rupa Kumar K and Rajeevan M 2009b Increasing influence of ENSO and decreasing influence of $\mathrm{AO} / \mathrm{NAO}$ in the recent decades over northwest India winter precipitation; J. Geophys. Res. 114(D12112), doi: 10.1029/2008JD011318.

Yadav R K, Yoo J H, Kucharski F and Abid M A 2010 Why is ENSO influencing northwest India winter precipitation in recent decades? J. Climate 23 1979-1993.

MS received 29 April 2011; revised 26 December 2011; accepted 26 December 2011 